\title{
A community-based case-control study of prevalence and pattern of cognitive impairments in patients with epilepsy residing in South-Eastern Nigeria
}

Eugene O. Arinzechi, Olubunmi A. Ogunrin¹, Cosmas M. Nwosu, Paul O. Nwani, Kelechi O. Enwereji, Lasbrey A. Asomugha, Uche Dimkpa²

Department of Medicine, Neurology Unit, Nnamdi Azikiwe University Teaching Hospital, ${ }^{2}$ Department of Human Physiology, Faculty of Basic Medical Sciences, Nnamdi Azikiwe University, Nnewi, 'Department of Medicine, Neurology Unit, University of Benin Teaching Hospital, Benin City, Nigeria

\begin{abstract}
Background: Epilepsy is the commonest neurological disorder encountered in Sub-Saharan Africa. The quality of life of patients with epilepsy (PWEs) is adversely affected by cognitive impairments. Aim: This study investigated the prevalence and pattern of cognitive impairments in PWE in Ukpo community located in a South-Eastern state in Nigeria using Community Screening Interview for Dementia (CSID) and a computer-assisted cognitive test battery (FePsy). Methods and Patients: Fifty-one PWEs were studied and compared with 51 age-, sex-and level of education-matched healthy controls. Diagnosis of epilepsy was confirmed clinically with eye-witness corroboration. Sociodemographic data and information on epilepsy variables were obtained with the aid of a questionnaire. Cognitive domains assessed include language, memory, orientation, attention, psychomotor speed and constructional praxis. Results: The prevalence rate of cognitive impairment using total CSID score was $19.6 \%$. Analysis of CSID scores revealed significant impairment in language (17.6\%), memory $(29.4 \%)$, orientation $(15.7 \%)$, attention $(7.8 \%)$ and constructional praxis (15.7\%) compared to healthy controls. A similar pattern was observed with FePsy but with better sensitivity indices for detecting cognitive impairment. Conclusion: This study indicated significant prevalence rate of cognitive impairment among treatment-naïve PWE with profound affectation of memory, mental speed and language. In addition, the FePsy was found to be more sensitive and specific in assessment of cognitive function in PWE.
\end{abstract}

Key words: Attention, cognition, epilepsy, language, memory, praxis

\section{Introduction}

The number of new cases of epilepsy in Sub-Saharan Africa (SSA) is on the increase, ranging between 64 and 156 per 100,000 people per year, ${ }^{[1]}$ and this may be attributed to poor perinatal management, recurrent

\section{Address for correspondence:}

Prof. A. Olubunmi Ogunrin, Department of Medicine, Neurology Unit, University of Benin Teaching Hospital, P.M.B. 1111, Benin City, Edo State, Nigeria.

E-mail: bfunmi@uniben.edu

\begin{tabular}{|l|l|}
\hline \multicolumn{2}{|c|}{ Access this article online } \\
\hline Quick Response Code: & Website: \\
\hline & www.ruralneuropractice.com \\
\hline & \\
\hline
\end{tabular}

childhood febrile convulsions, prevalent infectious diseases and traumatic brain injury. ${ }^{[2]}$ This region also has very high prevalence rates ranging between 2.2 and 58 per 1000 people, with higher rates associated with rural communities and lack of health care facility. ${ }^{[2-4]} \mathrm{A}$ recent study compared the prevalence in a rural Nigerian community with that of a semi-urban community and reported a rate of 20.8 per 1000 in the rural community, higher than the rate of 4.7 per 1000 in the semi-urban community. ${ }^{[4]}$ Partial epilepsies are the most common

This is an open access article distributed under the terms of the Creative Commons Attribution-NonCommercial-ShareAlike 3.0 License, which allows others to remix, tweak, and build upon the work non-commercially, as long as the author is credited and the new creations are licensed under the identical terms.

For reprints contact: reprints@medknow.com

How to cite this article: Arinzechi EO, Ogunrin OA, Nwosu CM, Nwani PO, Enwereji KO, Asomugha LA, et al. A community-based case-control study of prevalence and pattern of cognitive impairments in patients with epilepsy residing in South-Eastern Nigeria. J Neurosci Rural Pract 2016;7:405-11. 
worldwide and account for $76 \%$ of cases of epilepsy in Nigeria while generalized epilepsies account for $20 \%$ of epilepsy cases. Of the partial seizures, $29 \%$ are simple, $57 \%$ are complex, and $14 \%$ are with secondary generalization. ${ }^{[5]}$ Also, subjects with human leukocyte antigen-A9 haplotype have been reported to be 16 times more susceptible to develop epilepsy than the general population. ${ }^{[6]}$

The wide treatment gap is characteristic of SSA constituting a major challenge to management of epilepsy. This is further worsened by presence of cognitive impairments which may affect the patients' vocation, education, social $\operatorname{life}^{[7]}$ and medication adherence. ${ }^{[8]}$ The poor medication adherence has been demonstrated to be largely due to memory disturbance in a study of Nigerian patients with epilepsy (PWEs). ${ }^{[8]}$ Several studies have demonstrated cognitive disturbances in PWEs with the prevalence varying widely. ${ }^{[9-11]}$ Cognitive impairments may occur either ab initio from recurrent epileptic attacks or due to adverse effect of antiepileptic drugs. A study that evaluated cognitive function in Nigerians with newly diagnosed epilepsy before commencement of antiepileptic drug therapy using an automated cognitive test battery, the Iron Psychology (acronym-FePsy), revealed impairment of visual and auditory reaction times (ARTs), memory tasks and attention span. ${ }^{[12]}$ Another study has shown significant impairment in cognitive abilities of Nigerian PWEs using the Community Screening Instrument for Dementia (CSID). ${ }^{[13]}$ This cognitive impairment pattern has been reported by other authors. ${ }^{[14,15]}$

Despite the several studies demonstrating the cognitive impairments in Nigerian PWE, there has been no study that assessed prevalence among PWEs especially and define patterns of impairment in South-Eastern states of Nigeria. Therefore, this study investigated the prevalence and pattern of cognitive impairments in PWEs in Ukpo, Anambra State, South-East Nigeria, using CSID and FePsy cognitive tools.

\section{Methods and Patients}

\section{Study site}

Ukpo is a sub-urban community in Awka, the capital of a South-Eastern state in Nigeria. It has a population of 14,300 with estimated $65 \%$ above the age of 18 years. ${ }^{[16]}$ The inhabitants are mainly Igbos, and the major religion is Christianity with a few adherents to Africa traditional religion. The community's major diet is tuber-based with large consumption of palm oil. Cereal meals largely are prepared on special days and festive periods. Initial sensitization meetings with the community leaders, the herbalists, opinion leaders, the clergy men and school heads were done before commencement of the study.

\section{Patients with epilepsy}

Fifty-one patients (33 males and 18 females) aged 16-75 years diagnosed with epilepsy were selected by snowball technique from the Ukpo community clinic. Structured questionnaires designed to obtain demographic information on the age, sex, level of education, age at onset of seizures, history of fever, head injury, drug or alcohol abuse, systemic diseases that can result in symptomatic seizures, and seizure variables (frequency, duration and type of seizures) were completed for all study participants. The duration of epilepsy was estimated as the historic time interval between the first attack ever and the initial presentation at the Ukpo community clinic. The clinical diagnosis of epilepsy was based on history of two or more recurrent afebrile seizures and eye witness corroboration with electroencephalogram (EEG) confirmation. The seizure types were classified clinically based on the International League Against Epilepsy criteria. ${ }^{[17]}$ The exclusion criteria included subjects $<16$ years of age, patients with co-morbidities (i.e., diabetes mellitus, hypertension, and associated intracranial disorders, e.g., brain tumor, and other metabolic diseases), major axis 1 psychiatric illness, presence of clinical signs of cardiac, hepatic or renal failure, alcohol intake above $120 \mathrm{~g} /$ week or 13 units/week, history of previous head injury with loss of consciousness and patients on anticholinergic medications. Patients with visual and hearing impairment (because of interference with psychometric analysis), those who are unable to understand, communicate and follow instructions for the psychometric test were also excluded from the study.

\section{Controls}

Fifty-one healthy controls (comprising 33 males and 18 females) were recruited from the neighborhood of the PWEs within the same community. These were age-, sex- and level of education-matched with the PWEs. They had neither personal nor family history of seizures.

\section{Recruitment}

Snowball sampling technique was used to ensure identification of all cases of epilepsy in the community. The snowball technique involved finding the people who knew about the diseases in the community including herbalists, community leaders, opinion leaders, the clergy, and school heads to assist in identifying PWEs. Identified people with epilepsy were also asked to assist in further identifying other people with epilepsy. This continued until all the people with epilepsy were identified. The study lasted for about 3 months. EEG was done on all the patients. 
Seventy-five PWE were identified by the snowball method. Eighteen of them were aged $<16$ years; two had hearing and speech impairments; two had severe physical disability, and two were severely mentally impaired (they could not cope with the cognitive assessment). The remaining 51 satisfied the inclusion criteria and thus formed the sample of the study.

\section{Cognitive testing}

Community Screening Interview for Dementia (CSID) composed of 48 items with a 32-item cognitive test and a 16-item informant interview. The cognitive test covers the domains of memory (recall, registration), language (expression, naming, repetition and fluency), attention and calculation, orientation (to place and time), praxis and abstract thinking. It takes an average of $15 \mathrm{~min}$ to administer. CSID has been used in many populations from different socioeconomic backgrounds and has been translated and used among the African-Americans, Chinese, Taiwanese and Nigerian Yorubas. ${ }^{[18]}$

The CSID instrument was translated into the traditional Igbo language and back translated to ensure consistency. The translation was done by a university graduate secondary school teacher who holds a first degree in Igbo language. The CSID was administered to all PWEs and controls by one of the authors (A.E) in a room free of distractions. The CSID administration per participant lasted 15-25 min. The subtotal scores for each cognitive domain were calculated and the aggregate score was also calculated. Cognitive impairment cut-offs were determined by subtracting 2 standard deviation (SD) from mean values of the control subjects' subtotal scores of language, memory, orientation, and attention domains and total CSID score as previously documented by Salawu et al..$^{[19]}$ The cut-off values therefore were; 12.14 for language score, 3.72 for memory score, 4.15 for orientation score, 1.70 for attention score and 23.02 for total CSID score. Therefore, any value below these cutoffs were considered as cognitively impaired. In contrast, 2 SD was added to the mean control praxis score to obtain the cut-off score of 4.57 because the cognitive performance is inversely related to the praxis score. Any value above this cut-off was considered impaired.

The Iron Psychology (acronym-FePsy) ${ }^{[20]}$ cognitive test battery was used to assess the following tasks:

\section{The simple reaction time}

This has two components-the visual and auditory. The essence of this task is to assess the mental (psychomotor) speed of the individual. The reaction time for simple auditory and visual stimuli were measured. In the visual version, the testee was expected to react as quickly as possible on seeing a white square in the middle of the computer screen by pressing the space bar. The auditory version involves the presentation of sound stimuli of $800 \mathrm{~Hz}$ generated by the computer and the testee was asked to react as quickly as possible on hearing the sound by pressing the space bar.

The two tests were done using the dominant hand and nondominant hands. It had two phases: The learning phase and the test phase. In the learning phase (trial run) the testee was taught how to do the test according to the instructions on the computer screen. In the test phase, the testee carried out the instructions exactly as taught. Failure to do this after three consecutive trials disqualified the testee for the test. The interstimulus interval was randomly varied from 2.5 to $4 \mathrm{~s}$. For both the dominant and nondominant hands of each subject, 30 stimuli were presented for the auditory version and another 30 stimuli for the visual version. The results showed accuracy and speed of response in milliseconds. The evaluation of the results was done within the context of speed of information processing and alertness functions. The average of the scores in milliseconds was then analyzed and recorded automatically by the computer. The normal control reference values of ARTs for both dominant and nondominant hands were 492.02 $\mathrm{ms}$ and $484.85 \mathrm{~ms}$ respectively. For visual reaction times (VRTs) the values were 464.71 and $542.26 \mathrm{~ms}$ for dominant and nondominant hands respectively. Scores higher than the normal reference values were taken as abnormal.

\section{The recognition memory task}

This comprised the words and figures sections which were presented simultaneously to assess recall. The study items consisted of 4 figures (nonsense figures) or 6 words which were presented for $1 \mathrm{~s}$. In this test, the participant was shown an array of words and figures respectively and was expected to detect among subsequent words and figures, the words/figures, that appeared before. The task comprised of the learning phase and testing phase. One of the authors (A.E.) administered the learning phase to the participant, before the test phase. This task lasted for an average of $20 \mathrm{~min}$ per participant.

As mentioned earlier, the task was divided into a study phase in which the material to be remembered was presented and a test phase in which recognition (recall of study items) was tested. In the study phase, the subject was presented with 3 or 4 figures, or 4 or 6 words to study and memorize. In the recognition phase, different sets of 3 or 4 figures or 4 or 6 words were presented again and one of these matched one of the study items. The 
testee was required to identify the word or figure in the second presentation that matched one of the study items presented initially.

Patients with primary and secondary education were tested using the 3 figures and 4 words for visual and verbal memory respectively, while those in tertiary education were tested using the 4 figures and 6 words. Words were randomly selected from a pool of about 100 words. Figures were randomly built up from basic elements of triangles $(\Delta)$ and rectangles $(\square)$ and were difficult to label. The results were calculated as a percentage of correct responses. The evaluation of the recognition task was performed in the context of the recognition process within the memory function. The cut-off values for figure and word recognition were 59 and $73 \%$ respectively.

\section{Data analysis}

Analysis of data was aided by the use of SPSS (SPSS Inc. Chicago, USA) for Windows software (version 16.0). Descriptive data were expressed as mean and SD for continuous variables and as percentages for categorical variables. Comparative analysis of cognitive scores between PWE and controls was analyzed for significance using Student's $t$-test. Categorical variables between PWE and controls were analyzed using Chi-square distribution. Statistical significance was set at $P<0.05$.

\section{Results}

Fifty-one PWEs participated in the study. The mean age of the 51 PWE was $29.60 \pm 12.01$ years while that of the 51 matched controls was $31.43 \pm 12.85(t=0.74$; $P=0.46)$. There were 33 males and 18 females in the test group (PWE) similar to the distribution in the control group [Table 1]. Similarly, there was no significant difference in level of education of both groups $(P<0.5)$. Most of the PWEs were privately employed. Eighty-two percent of the PWEs had localization-related (focal) seizures. Long duration of epilepsy of $>6$ years was observed in $39(76.4 \%)$ of the PWEs [Table 2].

Analysis of the mean CSID total scores revealed significantly higher scores for the controls than the PWEs $(P<0.001)$. Similarly, a similar trend was observed for the subtotal scores for language scores $(P<0.001)$, memory scores $(P<0.001)$, attention scores $(P<0.01)$ but lower constructional praxis scores $(P<0.001)$ was expectedly recorded for the controls because of its inverse scoring technique [Table 3]. However, no significant difference was observed in orientation scores between healthy controls and PWE [Table 3].
Table 4 shows the cognitive impairment status in PWE using CSID scores. The prevalence of cognitive impairment using total CSID score was $19.6 \%$. The prevalence rates of cognitive impairment based on the cognitive domains using the CSID scores were as shown in the table. Table 5 shows the scores of the PWEs and controls with FePsy. The PWEs performed worse than the controls in all FePsy cognitive domains.

Independent sample $t$-test indicated significantly higher mean scores on testing of dominant ART (ART-D),

\begin{tabular}{|c|c|c|c|c|c|}
\hline \multirow[t]{2}{*}{ Variables } & \multicolumn{3}{|c|}{$n(\%)$} & \multirow[t]{2}{*}{$\chi^{2}$} & \multirow[t]{2}{*}{$P$} \\
\hline & $\begin{array}{l}\text { Healthy } \\
\text { controls }\end{array}$ & PWE & Total & & \\
\hline \multicolumn{6}{|l|}{ Age groups } \\
\hline $16-25$ & $22(43.1)$ & $22(43.1)$ & 44 (43.1) & 1.4 & 0.93 \\
\hline $26-35$ & $13(25.5)$ & $19(37.3)$ & $32(31.4)$ & & \\
\hline $36-45$ & $9(17.6)$ & $4(7.8)$ & $13(12.7)$ & & \\
\hline $46-55$ & $5(9.8)$ & $3(5.9)$ & $8(7.8)$ & & \\
\hline $56-65$ & $1(2.0)$ & $2(3.9)$ & $3(2.9)$ & & \\
\hline$>65$ & $1(2.0)$ & $1(2.0)$ & $2(2.0)$ & & \\
\hline Total & $51(100.0)$ & $51(100.0)$ & $102(100)$ & & \\
\hline \multicolumn{6}{|l|}{ Sex } \\
\hline Males & $33(64.7)$ & $33(64.7)$ & $66(64.7)$ & & \\
\hline Females & $18(35.3)$ & $18(35.3)$ & $36(35.3)$ & & \\
\hline Total & $51(100.0)$ & $51(100.0)$ & $102(100)$ & 0.65 & 0.42 \\
\hline \multicolumn{6}{|l|}{ Occupation } \\
\hline Publicly employed & $4(7.8)$ & $6(11.8)$ & $10(9.8)$ & $9.82^{\dagger}$ & 0.02 \\
\hline Privately employed & $30(58.8)$ & $18(35.3)$ & $48(47.1)$ & & \\
\hline Students & $8(15.7)$ & $21(41.1)$ & $29(28.4)$ & & \\
\hline Unemployed & $9(17.7)$ & $6(11.8)$ & $15(14.7)$ & & \\
\hline Total & $51(100.0)$ & $51(100.0)$ & $102(100)$ & & \\
\hline \multicolumn{6}{|l|}{ Level of education } \\
\hline Non formal & $5(9.8)$ & $5(9.8)$ & $10(9.8)$ & 1.67 & 0.64 \\
\hline Primary & $18(35.3)$ & $18(35.3)$ & $36(35.3)$ & & \\
\hline Secondary & $25(49.0)$ & $25(49.0)$ & $50(49.0)$ & & \\
\hline Tertiary & $3(5.9)$ & $3(5.9)$ & $6(5.9)$ & & \\
\hline Total & $51(100.0)$ & $51(100.0)$ & $102(100)$ & & \\
\hline
\end{tabular}

Table 2: Pattern of seizure variables $(n=51)$

\begin{tabular}{lc}
\hline Variables & Frequency (\%) \\
\hline Seizure types & \\
Focal & $42(82.4)$ \\
Generalized & $9(17.6)$ \\
Seizure frequency & \\
Several fits/days & $3(5.9)$ \\
$1-3$ attacks/weeks & $17(33.3)$ \\
$1-2$ attacks/months & $24(47.1)$ \\
Once/3-6 months & $7(13.7)$ \\
Duration of epilepsy (years) & \\
$<1$ & $3(5.9)$ \\
$1-5$ & $9(17.7)$ \\
$6-10$ & $22(43.1)$ \\
$>10$ & $17(33.3)$ \\
\hline
\end{tabular}


nondominant ART (ART-ND), dominant VRT (VRT-D) and nondominant VRT (VRT-ND) in PWE compared to healthy control $(P<0.001)$. However significantly higher mean recognition scores were observed among control subjects than the PWE $(P<0.001)$ indicating impaired memory ability among PWEs [Table 5].

\section{Discussion}

This study demonstrated significant cognitive impairment in PWEs residing in a well-defined suburban community in Awka, South Eastern part of Nigeria, with a prevalence rate of $19.6 \%$. The demographic information of the PWEs in this locality were similar to that reported by previous authors in the

\section{Table 3: Mean Community Screening Instrument for} Dementia scores in patients with epilepsy and healthy controls

\begin{tabular}{lcccc}
\hline \multirow{2}{*}{ CSID variables } & \multicolumn{2}{c}{ Mean \pm SD $(\boldsymbol{n}=\mathbf{5 1})$} & \multirow{t}{*}{$\boldsymbol{P}$} & $\boldsymbol{P}$ \\
\cline { 2 - 3 } & Controls & PWE & & \\
\hline Language & $25.53 \pm 5.87$ & $19.96 \pm 7.44$ & 4.19 & $0.000^{*}$ \\
Memory & $8.43 \pm 1.97$ & $5.41 \pm 2.82$ & 6.25 & $0.000^{*}$ \\
Orientation & $5.61 \pm 0.98$ & $5.25 \pm 1.06$ & 1.79 & 0.08 \\
Attention & $4.52 \pm 1.39$ & $3.58 \pm 1.37$ & 3.43 & $0.001^{*}$ \\
Constructional praxis & $1.92 \pm 1.35$ & $3.21 \pm 1.23$ & -5.03 & $0.000^{*}$ \\
Total CSID score & $42.18 \pm 8.12$ & $31.0 \pm 11.09$ & 5.81 & $0.000^{*}$ \\
\hline
\end{tabular}

*Significant $P<0.05$. CSID: Community Screening Instrument for Dementia, PWE: Patients with epilepsy, SD: Standard deviation

Table 4: Prevalence of cognitive impairment using Community Screening Instrument for Dementia scores in patients with epilepsy $(n=51)$

\begin{tabular}{lcc}
\hline CSID variables & PWEs with impairment & Percentage \\
\hline Language & 9 & 17.6 \\
Memory & 15 & 29.4 \\
Orientation & 8 & 15.7 \\
Attention & 4 & 7.8 \\
Constructional praxis & 8 & 15.7 \\
Total CSID & 10 & 19.6 \\
\hline
\end{tabular}

PWE: Patients with epilepsy, CSID: Community Screening Instrument for Dementia

Table 5: Mean FePsy scores in patients with epilepsy and healthy controls

\begin{tabular}{lccccc}
\hline $\begin{array}{l}\text { FePsy } \\
\text { variables }\end{array}$ & \multicolumn{2}{c}{ Mean \pm SD $(\boldsymbol{n = 5 1 )}$} & t-state & $\boldsymbol{P}$ & $\begin{array}{c}\text { Percentage } \\
\text { Healthy }\end{array}$ \\
\cline { 2 - 3 } & controls & PWE & & & $\begin{array}{c}\text { PWE } \\
\text { cognitively } \\
\text { impaired }\end{array}$ \\
\hline ART-D & $358.40 \pm 66.81$ & $980.79 \pm 315.15$ & -11.82 & 0.000 & 100 \\
ART-ND & $357.05 \pm 63.90$ & $912.41 \pm 372.47$ & -9.05 & 0.000 & 94.9 \\
VRT-D & $331.05 \pm 66.83$ & $898.25 \pm 191.66$ & -16.61 & 0.000 & 97.4 \\
VRT-ND & $361.60 \pm 90.33$ & $906.69 \pm 238.68$ & -12.60 & 0.000 & 97.4 \\
Figure & $76.45 \pm 8.36$ & $42.80 \pm 14.67$ & 9.23 & 0.000 & 86.4 \\
recognition & & & & & \\
\hline ART
\end{tabular}

ART-D: Auditory reaction time-dominant, ART-ND: Auditory reaction timenondominant, VRT-D: Visual reaction time-dominant, VRT-ND: Visual reaction time-nondominant, PWE: Patients with epilepsy, SD: Standard deviation literature, an important reflection that younger adults bear the brunt of epilepsy in developing countries. ${ }^{[2-4]}$ Not surprisingly, the prevalence of epilepsy in this suburban community was low as this may be related to the presence of a comprehensive health facility in the community. Previous studies have associated presence of health facility to low prevalence of epilepsy in Nigeria. ${ }^{[3,21]}$ Similarly, the long duration of epilepsy may be explained by late presentation of PWEs to health facilities as a previous study showed that more than $60 \%$ of PWEs seek traditional healers for assistance. ${ }^{[22]}$

Cognitive dysfunctions associated with epilepsy include memory impairment, psychomotor retardation, inattention and lack of concentration, reduced motor speed and in patients with significant brain damage impaired visual scanning task. ${ }^{[14,15,19]}$ Memory impairment was demonstrated among PWEs in this study, corroborating what has been reported by other workers in the literature. ${ }^{[23-25]}$ It has also been established that cognitive deterioration in people with epilepsy is associated with poor quality of life, academic disruption and social stigma. ${ }^{[26]}$

Attention and calculation were impaired in PWE when compared with control subjects. This is in agreement with previous studies..$^{[9,12,14,15]}$ Constructional praxis has been reported to be impaired in PWE. ${ }^{[13,26]}$ Most workers thought that this was due to dysfunction of visuo-spatial, visuo-attentional and visuo-constructional neuronal circuitry which may occur secondary to either recurrent seizures or an underlying brain disease. ${ }^{[27]}$ The performance on the orientation subscale of the CSID does not show statistical significant difference between PWE and the control. This is in agreement with the previous study by Imam and Ogunniyi. ${ }^{[28]}$ The reason for this is not obvious from this study.

The performance of the PWEs revealed higher percentages of cognitive impairment with FePsy tasks than with CSID. The severity of cognitive impairments observed with FePsy was significantly higher than what has been reported by several other authors. This may be due to differences in cognitive tools used and the methodological approach of the previous studies. For instance, the higher sensitivity of the FePsy, being a computer-assisted test battery, may explain the higher prevalence figures for cognitive impairment observed in our study when compared to earlier reports.

The FePsy assesses the working memory of individuals because the memory task utilized for this study is the 
Recognition Memory Test which measures recall ability of the testee. Recall deficiency has been previously described in epilepsy, especially with verbal memory. ${ }^{[29]}$ It is responsible for the poor quality of life in epilepsy especially with regards to medication adherence, educational achievement and coping with vocational skills. ${ }^{[7,8]}$ Though the effect of medication use on quality of life in epilepsy is complex to evaluate, ${ }^{[30]}$ the contribution of antiepileptic drugs to cognitive impairments may negatively affect quality of life. ${ }^{[31]}$ Unfortunately, this study did not evaluate the effects of seizure variables on the cognitive performances of the PWEs.

The deterioration of psychomotor ability is a common finding in PWE especially those with generalized seizures. This is depicted in this study by the prolonged auditory and VRTs which corroborate observations of other authors. ${ }^{[12,32,33]}$ Interestingly, the dominant hand ART was more prolonged than the VRT in the controls. This was similar to the report by Ogunrin et al. ${ }^{[12]}$ However this is at variance with FePsy scores obtained among Europeans in which ARTs are at least $60 \mathrm{~ms}$ faster than visual. ${ }^{[34]}$ This may be related to the higher prevalence of recurrent childhood febrile seizures in Nigeria, which have been linked with mesial temporal sclerosis, thereby affecting the temporal lobes functioning of PWEs in Nigeria more severely.

\section{Conclusion}

This study revealed that the prevalence of cognitive impairment using total CSID score was $19.6 \%$ and for the cognitive domains, using FePsy, the rate was $100 \%$ for ART-D, 94.9\% for ART-ND, 97.4\% for (VRT-D and VRT-ND hand) and $86.4 \%$ for recognition memory task. There is significant cognitive decline affecting the domains of language, memory, attention and constructional praxis in PWE when compared to controls. FePsy is particularly more sensitive in assessment of cognitive function in PWE. The appreciation of the pattern of these cognitive impairments will aid academic, vocational and social counseling, and encourage regular cognitive assessment of PWEs to prevent the adverse consequences of cognitive dysfunction.

\section{Limitations}

The limitations of this study include the small sample size which does not allow for application of sophisticated statistical methods to improve fundamental understanding of the effects of different medical and sociodemographic variables on cognitive function in PWEs and may be difficult to generalize the findings to other suburban communities. Furthermore, we did not evaluate the impact of the various seizure variables like type, duration, and frequency of seizures on cognitive performance as this is beyond the scope of this paper.

\section{Financial support and sponsorship \\ Nil.}

\section{Conflicts of interest}

There are no conflicts of interest.

\section{References}

1. Preux PM, Druet-Cabanac M. Epidemiology and aetiology of epilepsy in sub-Saharan Africa. Lancet Neurol 2005;4:21-31.

2. Ngugi AK, Bottomley C, Kleinschmidt I, Wagner RG, Kakooza-Mwesige A, Ae-Ngibise K, et al. Prevalence of active convulsive epilepsy in sub-Saharan Africa and associated risk factors: Cross-sectional and case-control studies. Lancet Neurol 2013;12:253-63.

3. Ogunrin OA, Obiabo OY, Obehigie E. Risk factors for epilepsy in Nigerians-a cross-sectional case-control study. Acta Neurol Scand 2014;129:109-13.

4. Osakwe C, Otte WM, Alo C. Epilepsy prevalence, potential causes and social beliefs in Ebonyi State and Benue State, Nigeria. Epilepsy Res 2014;108:316-26.

5. Danesi MA. Classification of the epilepsies: An investigation of 945 patients in a developing country. Epilepsia 1985;26:131-6.

6. Hafez M, Nagaty M, Saied E. HLA antigens and idiopathic epilepsy. Epilepsia 1985;26:15-8.

7. McNelis AM, Johnson CS, Huberty TJ, Austin JK. Factors associated with academic achievement in children with recent-onset seizures. Seizure 2005;14:331-9.

8. Ogboi SJ, Farounbi B, Adeleye AO, Ogunrin O, Agu PU. Evaluation of factors influencing medication adherence in patients with epilepsy in rural communities of Kaduna State, Nigeria. Neurosci Med 2011;2:299-305.

9. Huang $\mathrm{CW}$, Hsieh YJ, Tsai JJ, Pai MC. Cognitive performance in cryptogenic epilepsy. Acta Neurol Scand 2005;112:228-33.

10. Allegri RF, Drake M, Thomson A. Neuropsychological findings in patients with middle temporal lobe epilepsy. Rev Neurol 1999;29:1160-3.

11. Griffith HR, Martin RC, Bambara JK, Marson DC, Faught E. Older adults with epilepsy demonstrate cognitive impairments compared with patients with amnestic mild cognitive impairment. Epilepsy Behav 2006;8:161-8.

12. Ogunrin O, Adamolekun B, Ogunniyi AO, Aldenkamp AP. Cognitive function in Nigerians with newly diagnosed epilepsy. Can J Neurol Sci 2000;27:148-51.

13. Sunmonu TA, Komolafe MA, Ogunrin AO, Ogunniyi A. Cognitive assessment in patients with epilepsy using the Community Screening Interview for Dementia. Epilepsy Behav 2009;14:535-9.

14. Elger CE, Helmstaedter C, Kurthen M. Chronic epilepsy and cognition. Lancet Neurol 2004;3:663-72.

15. Dodrill CB. Neuropsychological effects of seizures. Epilepsy Behav 2004;5 Suppl 1:S21-4.

16. Federal Government of Nigeria. Census Figures, Nigeria; 2006. Available from: http://www.nigeriamasterweb.com/Nigeria06CensusFigs. html. [Last accessed on 2014 Dec 08].

17. Commission on Classification and Terminology, International League Against Epilepsy. Prepared revisions of clinical and electroencephalographic classification of epileptic seizures. Epilepsia 1981;22:480-501.

18. Hall KS, Gao S, Emsley CL, Ogunniyi AO, Morgan O, Hendrie HC. Community screening interview for dementia (CSI 'D'); performance in five disparate study sites. Int J Geriatr Psychiatry 2000;15:521-31.

19. Salawu FK, Bwala SA, Wakil MA, Bani B, Bukbuk DN, Kida I. Cognitive function in HIV-seropositive Nigerians without AIDS. J Neurol Sci 2008;267:142-6.

20. The Psychological Company. FePsy, A Neuropsychological Computerized Test Battery; 2008. Available from: http://www.fepsy.com. [Last assessed on 2009 Oct 08].

21. Osuntokun BO, Adeuja AO, Nottidge VA, Bademosi O, Olumide A, 
Ige $\mathrm{O}$, et al. Prevalence of the epilepsies in Nigerian Africans: A community-based study. Epilepsia 1987;28:272-9.

22. Ogunrin OA, Adeyekun A, Adudu P. Etiologies of epilepsy and health-seeking itinerary of patients with epilepsy in a resource poor setting: Analysis of 342 Nigerian Africans. Seizure 2013;22:572-6.

23. van Rijckevorsel K. Cognitive problems related to epilepsy syndromes, especially malignant epilepsies. Seizure 2006;15:227-34.

24. Mazarati A. Epilepsy and forgetfulness: One impairment, multiple mechanisms. Epilepsy Curr 2008-Feb; 8:25-6.

25. Helmstaedter C, Kurthen M, Lux S, Reuber M, Elger CE. Chronic epilepsy and cognition: A longitudinal study in temporal lobe epilepsy. Ann Neurol 2003;54:425-32.

26. Thomas SV, Nair A. Confronting the stigma of epilepsy. Ann Indian Acad Neurol 2011;14:158-63.

27. Gross RG, Grossman M. Update on apraxia. Curr Neurol Neurosci Rep 2008;8:490-6

28. Imam I, Ogunniyi A. The value of the mini mental state examination in Nigerian epileptics. Trop Doct 2005;35:108-9.

29. Weintrob DL, Saling MM, Berkovic SF, Berlangieri SU, Reutens DC.
Verbal memory in left temporal lobe epilepsy: Evidence for task-related localization. Ann Neurol 2002;51:442-7.

30. Brabcova D, Kohout J. What are the predictors of quality of life of people with epilepsy? J Neurosci Rural Pract 2013;4 Suppl 1:S5-6.

31. Piperidou C, Karlovasitou A, Triantafyllou N, Dimitrakoudi E, Terzoudi A, Mavraki E, et al. Association of demographic, clinical and treatment variables with quality of life of patients with epilepsy in Greece. Qual Life Res 2008;17:987-96.

32. Ogunrin AO, Adamolekun B. Cognitive neuro-assessment in Nigerian Africans: Predictive validity of a computerized testing. Ann Biomed Sci 2007;6:28-44.

33. Pulliainen V, Kuikka P, Jokelainen M. Motor and cognitive functions in newly diagnosed adult seizure patients before antiepileptic medication. Acta Neurol Scand 2000;101:73-8.

34. Aldenkamp AP, Baker G, Mulder OG, Chadwick D, Cooper P, Poelma J, et al. A multicentre randomized clinical study to evaluate the effect on cognitive function of topiramate compared with valproate as add on therapy to carbamazepine in patients with partial onset seizures. Epilepsia 2000;41:1167-78. 